\title{
Proceeding
}

Supplementary Issue: Winter Conferences of Sports Science. Costa Blanca Sports Science Events, 22-23 March 2021. Alicante, Spain.

\section{Measuring the consistency of accuracy of hand-to-eye alignment using an innovative computer-programmed device for young volleyball players}

\author{
RAJA ABDULSAMAD ASHOOR $\triangle$, WATHIQ ABDULSAHIB OUBED, AQEEL JAREH SABR \\ College of Physical Education and Sports Sciences, Basra University, Iraq
}

\begin{abstract}
The study aimed to identify the level of stability and accuracy of the compatibility between the hands and the eyes of the ballplayers for a plane according to their specializations, as well as to identify the differences between them. (12) Libero players (8) Fast players (10) High players (14) The fourth chapter included presenting and analysing the results after statistically treating them. As for the most important conclusions, the test was conducted between players and players of the team and individual games who use the right side and others who use the left side. The most important recommendations are that the trait of compatibility is a kinetic characteristic, and the higher the level of the player in this trait, the higher his level in the game, the higher his level in the game, and he must train on this trait during the training unit and make comparisons between the sexes to find out their true level and know what is distinguished from the other while identifying the variables that affect it.
\end{abstract}

Keywords: Consistency; Accuracy; Innovative.

\section{Cite this article as:}

Ashoor, R.A., Oubed, W.A., \& Sabr, A.J. (2021). Measuring the consistency of accuracy of hand-to-eye alignment using an innovative computer-programmed device for young volleyball players. Journal of Human Sport and Exercise, 16(3proc), S1444-S1449. https://doi.org/10.14198/jhse.2021.16.Proc3.60

Corresponding author. College of Physical Education and Sports Sciences, Basra University, Iraq.

E-mail:Dr.Raja70@yahoo.com

Abstract submitted to: Winter Conferences of Sports Science. Costa Blanca Sports Science Events, 22-23 March 2021. Alicante, Spain.

JOURNAL OF HUMAN SPORT \& EXERCISE ISSN 1988-5202.

(c) Faculty of Education. University of Alicante.

doi:10.14198/jhse.2021.16.Proc3.60 


\section{INTRODUCTION}

The tests conducted by the researchers are nothing but indications of the extent of the compatibility ability of the players on the playing field, and it is a pleasure and joy for the player to feel the excitement through an electronic means that the researchers follow in their tests in measuring some physical, motor or mental characteristics. The difference that separates them is the real level only, and the reason is the stability of the performance of the test stages as well as the evaluation mechanism and that the computer is the one that performs the evaluation. In the judgment and intended or unintended bias, as the judgment issued by the tester traditionally is subject to error sometimes or inaccuracy in issuing a judgment, unlike the computerbased tests that are limited in time where all the test conditions are uniform, which makes the test More honest and more faithful, a representation of the level of the research sample in terms of the interpretation of the test outcomes, we find a logical explanation that does not contradict the theories explaining the behaviour of pleasure For whom or the testers if the research sample follows the normal distribution, which is the basic condition for starting the research.

The research problem revolves around the lack of tests that measure mental qualities in which all test variables are combined in terms of standardizing the period and measuring all variables affecting the test such as the number of standardized attempts for all and measuring the number of correct and wrong attempts and their periods, not to mention measuring the final indicator within the computerized test, which gives $\mathrm{A}$ real evaluation of the level. Especially since the computerized tests in programming languages and for each test from the appearance of the interfaces or calculating the periods are accurate, and the time it takes for the test to obtain the result is considered ideal compared to the time taken to obtain the result with the paper and pen tests, ${ }^{2}$ which encouraged the researchers in making a special mechanism to perform the test, relying on linear programming, which is considered one of the best means to obtain the values of the test variables so that the test comes out accurately, which makes reassurance in the hearts of the testers.

\section{OBJECTIVES}

1. Identify the level of stability and accuracy of compatibility between hands and eyes of volleyball players according to their specialities.

2. Identify the differences in the level of stability and accuracy of the compatibility between hands and eyes between volleyball players according to the different playing specialities.

3. Identify the relationship between the level of stability accuracy of the compatibility between hands and eyes and between some variables (age, height, weight, and the user).

\section{Research field}

- The human field: Young volleyball players in Basra Governorate for the 2019-2020 sports season

- Time field: represented by the period from 1/10/2019 to 1/3/2020

- Spatial field: sports stadiums and halls for clubs in Basra Governorate.

\section{METHODOLOGY}

The researchers used the descriptive approach, which is the method used by researchers to obtain comprehensive and accurate information depicting the social reality that affects all activities. 


\section{Research community}

The community and the research sample are represented by the young volleyball players in Basra governorate for the academic year 2019-2020, and the number of (44) players according to their specializations is also indicated by the prepared players, their number (12) the Libero players (8) the fast players (10) the high players (14).

\section{The test used in the research}

- Test name: Rajaa test to measure the consistency of the accuracy of the compatibility between hands and eyes.

- The purpose of the test: To measure the level of consistency with the accuracy of the compatibility between hands and eyes.

- The tools used: A laptop computer with the following specifications (RAM 4KA - Hard 500KA processor speed $2 \mathrm{Ka} \mathrm{Hz}$ - processor type Core i5) - A special test created in the language of Faull Basic Sixth Edition

- The test lever with 30 numbered selection buttons starting from number 1 and ending with the number 30 button are distributed randomly on the test drum. All buttons must be pressed in succession from number 1 up to number 30 . These buttons are connected with the computer with a wire between them in an intermediate electronic circuit (Figure 1).

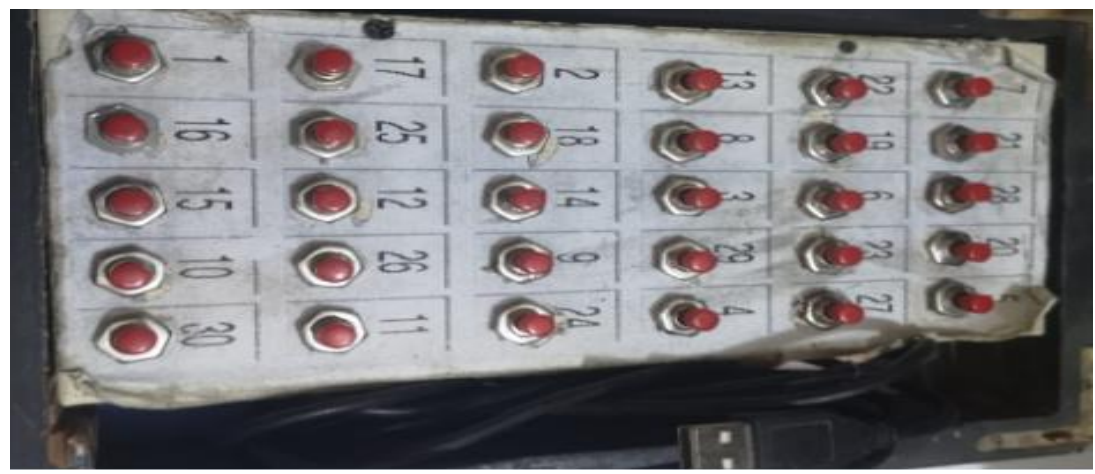

Figure 1. Shows the keyboard box to test the accuracy of the compatibility between hands and eyes.

- Performance method: After running the test on the computer through the icon on the desktop, the following window appears, Figure (2), through which one of the following options is chosen (start new), display data (DISPLAY DATA), or evaluation display (EVALUATION) As shown in Figure (2).

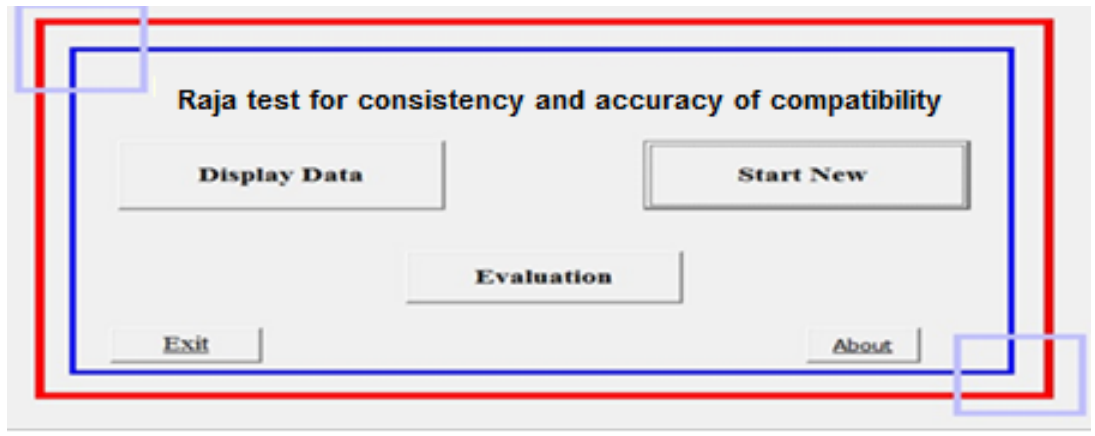

Figure 2. Show Rajaa's test for consistency accuracy. 
As for when choosing a new test (start new), the following window appears, Figure (3), in which the important data is entered.

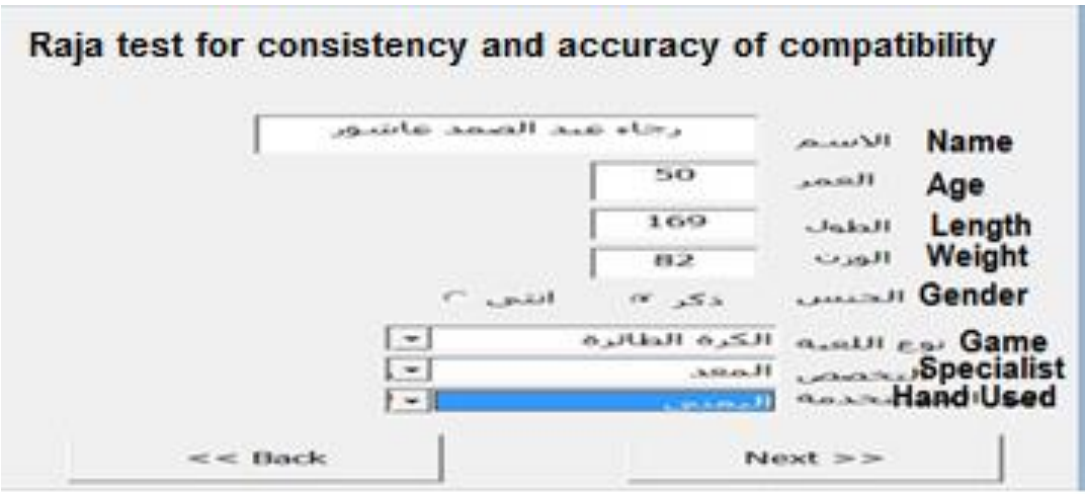

Figure 3. Illustrates the important data entry.

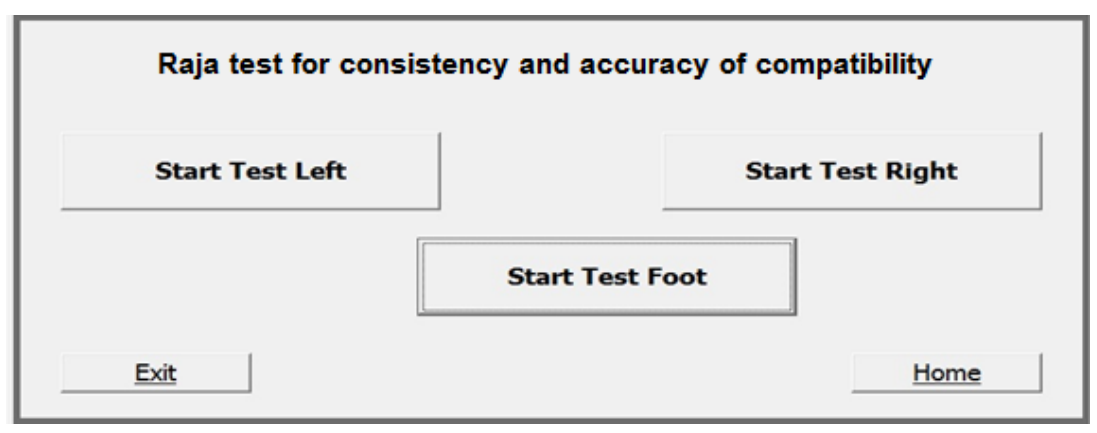

Figure 4. Shows Raja test for consistency and accuracy of compatibility.

And when you click on the right-hand select button, the following window appears Figure (5).

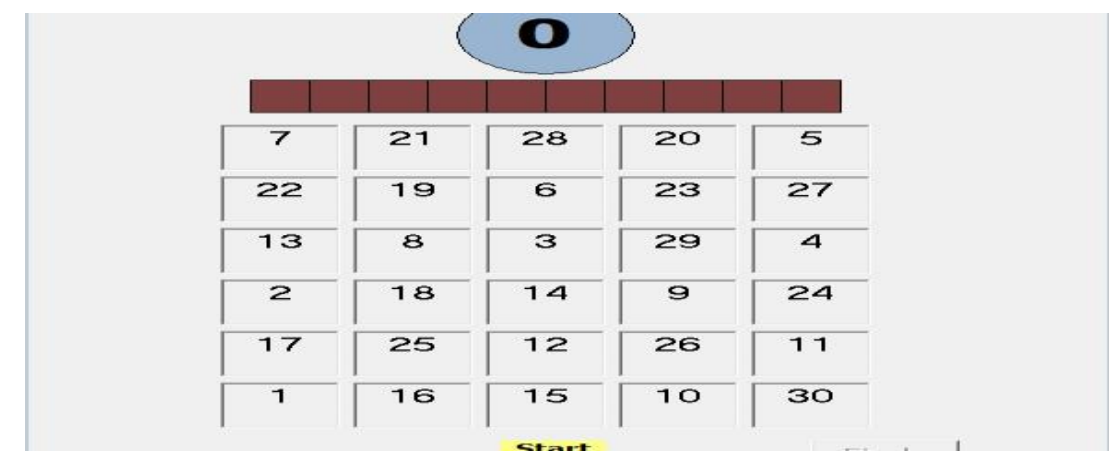

Figure 5. The reliability test demonstrates compatibility accuracy.

Then the clock appears, at which time the player prepares to start the test until the sound is heard as an indicator to start the test, and then it begins by clicking from the number (1) until it ends with the number (30) knowing that the numbers are random and unordered. 


\section{RESULTS AND DISCUSSION}

Table 4. Presentation of the results of the analysis of variance for the calculated and tabular $(F)$ value to test the reliability of the accuracy of the compatibility between hands and eyes of volleyball players according to different disciplines.

\begin{tabular}{lcccccc}
\hline Source of Variation & SS & df & MS & F & P-value & F crit \\
\hline Between Groups & 1580.345 & 3 & 526.7817 & 5.396804 & .003253692 & 2.838745406 \\
Within Groups & 3904.397 & 40 & 97.60993 & & & \\
Total & 5484.742 & 43 & & & & \\
\hline
\end{tabular}

It can be seen from Table (4) that the calculated value of $(F)$ of (5.396804) is greater than the table value of (F) of (2.838745406), and this indicates the existence of differences in the test of the stability accuracy of the compatibility between hands and eyes of volleyball players according to different disciplines, so we resort to the test The lowest moral teams (LSD), to know which specialities outperform the others.

Table 5. Presenting the results of the differences between the arithmetic averages and the value of the least significant difference to test the reliability of the accuracy of the compatibility between the hands, hands and eyes of volleyball players according to different disciplines.

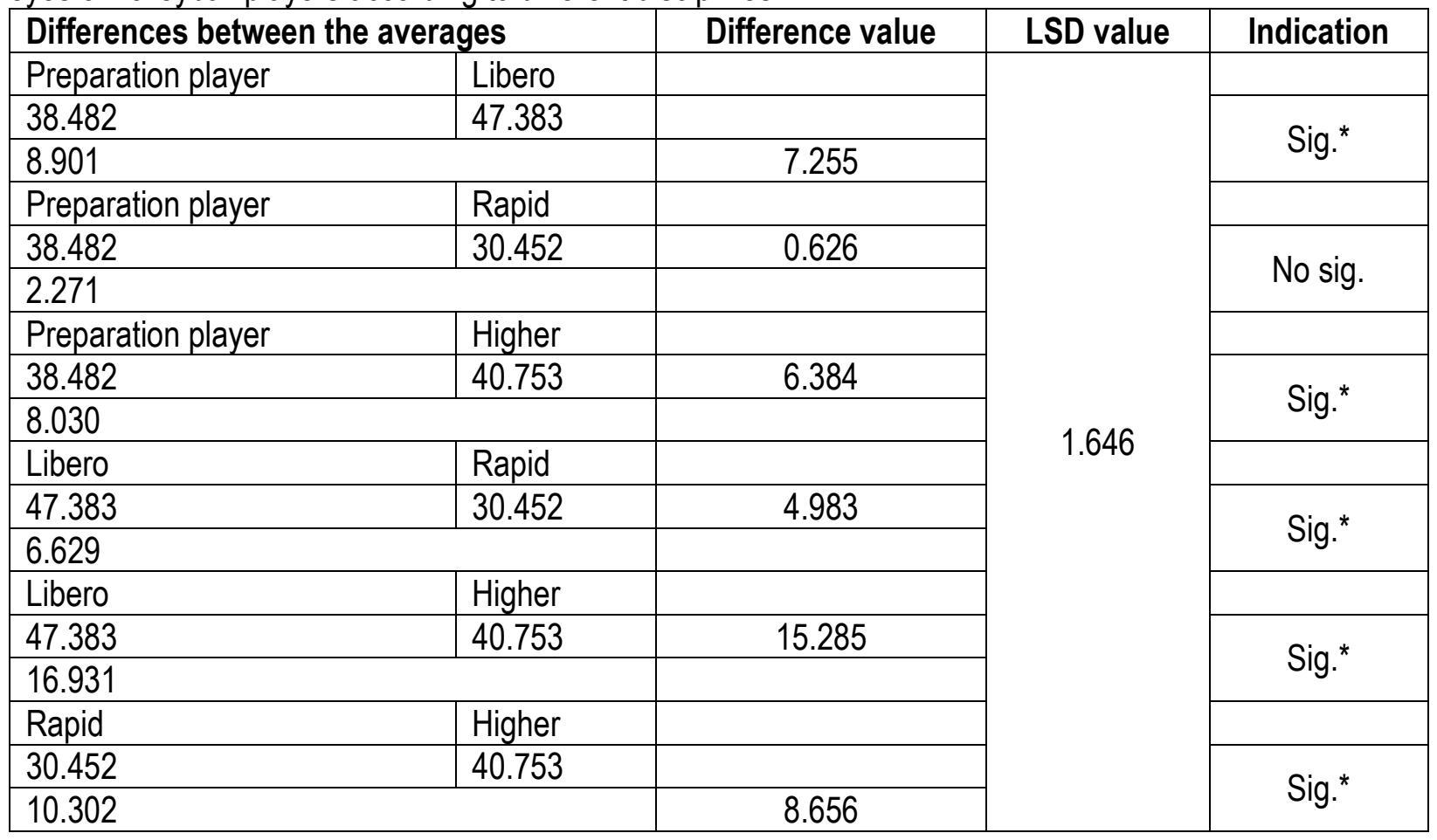

From Table (5) it was found that the prepared player was the best in maintaining the concentration of compatibility of the high player, the fast player and the free player. The competitor for the formation of successful and fruitful attacks, as well as the owner of the largest share of touches of the ball, where the goal of the ball received from the server or the state of defence is to deliver it to the player prepared for that. He had a great specificity of physical, movement and mental preparation to keep his mental and physical ability at its highest levels for the longest time It is possible. The process of conforming people to positions is subject to a set of factors that make him draw a map of duty in his mind, where perceptions arrive through his senses 
in the form of pictures, words and attitudes. To increase the effectiveness of reconciliation, we have to identify the common factors with him such as the senses and have special exercises for them.

The harmonization process is the organization of work between the central nervous system and the peripheral nervous system to control the body's capabilities to move and this process takes place within the cerebral cortex and leads to the work of the muscular system and this process is subject to the rule of fatigue resulting from physical changes Intracellular.

The fast player also came second in the level of this characteristic, and the researchers attribute that to the fact that the fast player should have this kinetic characteristic because he deals with duties on the field that require a high harmony ability, as the last player hits balls of different height from the middle of the net and close to the prepared player also hits the balls From the front and back of the equipment, and his duties are to intercept the attacks of the fast player of the opposing team and participate in the formation of the double and triple blocking wall on both sides of the network and all these movements need a lot of coordination and neuromuscular compatibility for his movements and the movements of colleagues and competitors, One of the duties of the fast defensive player is to read the type, location and type of the offensive compound, and to monitor the opposing player.

\section{CONCLUSIONS}

1. The test measures the consistency of the compatibility accuracy of the research sample.

2. The test can differentiate between the predominant movement limbs in use from others in use.

3. The test differentiates in the level of stability accuracy of compatibility between the different playing disciplines in the volleyball team.

\section{REFERENCES}

Athab, N. A. (2019). An Analytical Study of Cervical Spine Pain According to the Mechanical Indicators of the Administrative Work Staff. Indian Journal of Public Health Research \& Development, 10(5), 1348-1354. https://doi.org/10.5958/0976-5506.2019.01184.7

Athab, N. A., Hussein, W. R., \& Ali, A. A. M. (2019). A Comparative Study for Movement of Sword Fencing Stabbed According to the Technical Programming in the Game of Fencing Wheelchairs Class B. Indian Journal of Public Health Research \& Development, 10(5), 1344-1347. https://doi.org/10.5958/0976-5506.2019.01183.5

Maytham Saeed Salman. (2012). The Torture of NLP, Dar Al Zalaa, Beirut, Lebanon.

Rajaa Abd Al-Samad Ashour. (2012). Design and Standardization of Tests for Some Mental Abilities and the Flexibility of the Longitudinal Axis of the Body Using Computer Technology, PhD Thesis, Basra University, College of Physical Education.

Tariq Hassan Razzouki and Hussein Sobhan Sakhi. (2011). Volleyball Teaching Training for Team Building and Leadership, Rules of the Game, The Good Word, Najaf Al-Ashraf.

Wissam Salah Abdel-Hassan and Samer Youssef Mutaib. (2014). Kinetic Learning and its Applications in Physical Education and Sports, Dar Al-Kutub Al-Ilmiyya, Beirut, Lebanon.

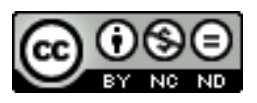

This work is licensed under a Attribution-NonCommercial-NoDerivatives 4.0 International (CC BY-NC-ND 4.0). 